\title{
O texto, o livro, o sentido e o leitor
}

\author{
Text, book, meaning and reader
}

\section{Márcio Souza Gonçalves}

Universidade do Estado do Rio de Janeiro - UERJ - Rio de Janeiro - Brasil

\begin{abstract}
Resumo: Discute-se a questão da produção de sentido na comunicação letrada através da abordagem de três apresentações diferentes dos Evangelhos: uma apresentação manuscrita, uma impressa e uma digital. Partindo de uma distinção entre "texto" e "livro", defende-se a ideia de que os suportes materiais são importantes na construção dos sentidos sem contudo relegar ao segundo plano, como pouco importantes, as questões dos usos, das apropriações dos leitores e, obviamente, do texto. É desenhada uma proposta de cartografia mínima para o mapeamento da produção de sentido, envolvendo o texto, os aspectos materiais de sua apresentação, a dimensão individual e a social dos leitores.
\end{abstract}

Palavras-chave: Sentido. Manuscrito. Impresso. Digital. Texto.

Abstract: The issue of meaning production in written communication is discussed through the analysis of three different material presentations of the Gospels: a handwritten codex, a printed book and a tablet. Starting with a distinction between "text" and "book", the paper states that material supports are important in the construction of meaning without, however, relegating to the background, as unimportant, questions of uses, appropriations by readers and, of course, the text. A minimal cartography designed to map the production of meaning in reading is proposed, involving the text, the material aspects of its presentation, the individual and social dimension of the readers.

Key-words: Meaning. Manuscript. Printed. Digital. Text. 


\section{Introdução ${ }^{1}$}

Desenvolve-se aqui a ideia de que o sentido de uma obra envolve, para além do texto que a constitui, outros elementos de caráter material, individual e social. Não se trata, obviamente, de anular a importância do texto, que é fundamental, mas antes de situá-la em relação a uma constelação de outros fatores também relevantes.

Serão tratadas três apresentações diferentes dos quatro Evangelhos canônicos, tendo como horizonte de discussão o que seja o sentido de um livro. Tal exploração será realizada, em primeiro lugar, através de uma abordagem da apresentação material das três exposições dos Evangelhos. Passase então a uma discussão dos diversos elementos em ação na produção do sentido desses livros, em três âmbitos distintos: material, individual, social. Concluise com uma tentativa de síntese da discussão em torno da questão do sentido de um livro, ou dos sentidos, no plural, como se verá.

\section{Livro e texto}

A distinção proposta por Leah Price em sua investigação acerca dos usos de livros, notadamente usos envolvendo processos outros que não a leitura, na literatura da Inglaterra vitoriana, pode ser útil. Assim a autora situa sua pesquisa:

As páginas que seguem reconstroem os modos de compreensão do século XIX e os sentimentos em relação aos usos da matéria impressa. Elas escavam especialmente relações muitas vezes litigiosas entre três operações: leitura (fazer algo com as palavras), manuseio (fazer algo com o objeto) e circulação (fazer algo para, ou com, outras pessoas através do livro - seja cimentando ou tensionando relações, seja dando ou recebendo livros ou retendo ou rejeitando-os). Frequentemente retratados como competindo, esses três modos, na prática, quase sempre se sobrepõem (PRICE, 2013, p. 5-6. A tradução das citações indicadas em língua estrangeira nas Referências é nossa).

\footnotetext{
${ }^{1}$ Uma versão preliminar do presente artigo foi apresentada no XXXIX Congresso Brasileiro de Ciências da Comunicação - GP Produção Editorial.
}

Para tratar adequadamente esse jogo de usos envolvido na leitura, manuseio e circulação do material impresso, Price propõe uma distinção entre texto (text no original) e livro (book no original). Texto (que grafaremos em itálico quando no sentido pretendido por Price) é o elemento abstrato composto por um ou mais autores, é a sequência de vocábulos ordenados linearmente no espaço e no tempo, "uma linha de palavras" (PRICE, 2013, p. 4). Livro (idem), por outro lado, é o objeto material que permite a encarnação do texto, é a coisa onde as palavras do autor se materializam, é o que permite o acesso ao texto, é uma "coisa física" (PRICE, 2013, p. 4).

Os Vitorianos investiam positivamente no texto na mesma proporção em que rejeitavam o livro. Mais especificamente, eles se identificavam como amantes de texto na mesma proporção em que se distinguiam dos amantes de livros. [...] Sempre que uma resenha menciona o preço ou aparência de um livro, sabemos que seu conteúdo textual será seja ridicularizado seja descartado como conteúdo inferior. Mesmo na era digital, nomear os componentes de um livro é insultálo - como quando um professor do MIT se refere a "escamas de árvore encerradas em uma vaca morta" ou um pesquisador da Microsoft a "marcas escuras em árvores retalhadas" (PRICE, 2013, p. 4-5)

A partir da distinção de Price, destacamos dois pontos.

Em primeiro lugar, um texto é dotado de certa estabilidade, mas essa estabilidade não é absoluta. Dotado de certa estabilidade na medida em que as palavras, grosso modo, estão arranjadas em uma sequência que geralmente se mantém. Assim, por exemplo, o texto da Crítica da Razão Pura, de Kant, é reconhecível por conter palavras ordenadas de uma certa forma; se essa ordenação inexistisse o texto perderia sua identidade. Por outro lado, a estabilidade textual não é absoluta, na medida em que as palavras podem ser reorganizadas, algumas retiradas, outras acrescentadas, em diferentes edições de uma mesma obra (veja-se o exemplo da própria obra de Kant citada acima, que foi alterada pelo autor depois da primeira edição). Essa entidade abstrata que é o texto, assim, mesmo sendo dotada de uma identidade, pode sofrer alterações em sua existência. Além disso, obras muito antigas e de autoria 
problemática podem propiciar ferrenhas discussões acerca de qual é o texto verdadeiro, o que abre o imenso campo do estabelecimento de textos com todas as dificuldades envolvidas.

Em segundo lugar, lembramos que é preciso ter em mente que um mesmo texto pode tomar corpo em livros radicalmente distintos. Por radicalmente distintos entende-se mais do que uma simples variação remetendo, por exemplo, para diferentes edições, tamanho do papel, mudanças na capa ou nos tipos empregados. A diferença pode ser mais profunda, como quando um texto apresentado originalmente em um livro antigo em formato de rolo recebe uma edição moderna em códice e são introduzidas a separação de palavras e a pontuação. Temos então dois elementos estruturais que não estavam presentes no livro "original" (o autor, quando materializou seu texto, não os utilizou) e foram introduzidos em edições posteriores (em geral muito posteriores). Equivocidades motivadas pela não separação de palavras podem produzir problemas de leitura, podem levar a que não se compreenda corretamente o texto, equivocidades que uma edição moderna com separação de palavras "resolve". Para tomar um caso famoso: Virgílio escreveu "collectam exilio pubem", "um povo reunido para exílio", e, em escrita contínua, chegou a ser entendido como "collectam ex llio pubem", "um povo reunido de Troia" (cf. GONÇALVES e TIMPONI, 2012, p. 61), o que nunca aconteceria em um texto impresso contemporaneamente com distinção entre palavras. Vê-se assim que, no limite, o livro pode mesmo influenciar o texto.

\section{0 sentido}

Tomando como base a diferenciação entre texto e livro e essas duas observações pontuais, podemos situar, inicialmente, o problema do sentido de uma obra qualquer.

A resposta mais óbvia e superficial acerca do sentido de uma obra o situaria no texto, que de algum modo conteria em si a intenção autoral. O autor teria pretendido apresentar um sentido e para isso teria escrito seu texto, ou seja, a ordenação de determinadas palavras de modo específico seria o veículo para a transmissão do sentido primeiro criado pelo escritor.

Ainda seguindo o caminho tradicional do óbvio, esse sentido seria independente dos diferentes livros em que o texto poderia aparecer editado. Desse modo, por exemplo, o sentido de Moby Dick estaria no texto de Melville e transcenderia as diversas apresentações materiais do romance, apresentações materiais que não o, ao sentido, afetariam.

O caráter problemático dessa resposta ligeira fica mais ou menos evidente conforme se investigue com alguma profundidade como um livro é lido e experienciado: o mesmo texto em uma edição barata e em uma edição de luxo pode ganhar, no ato da leitura, sentidos diferentes; o mesmo texto lido em momentos históricos diferentes é diferentemente interpretado etc.

Assim, seguindo autores ilustres, cujo conjunto da obra aborda direta ou indiretamente essa questão (McKenzie e Chartier, para citar apenas dois), é preciso que se abandone a ideia de um texto transcendental atemporal portador do sentido puro; é necessário que se incorpore, de algum modo, a ideia de que o sentido se produz no encontro entre texto, leitor e livro, e de que, consequentemente, o livro, assim como o leitor, sejam vistos como fazendo parte do sentido, como elementos participantes na construção do sentido de uma obra. Existem, em suma, textos que sempre se materializam em livros e ganham sentidos mais ou menos diferentes em função dos contextos em que são lidos, dos sujeitos leitores, do momento histórico em que a leitura se dá e assim por diante.

Além disso, é preciso que se leve em conta, como dito acima, que o próprio texto tem uma história e pode sofrer alterações mais ou menos importantes.

Toma-se aqui, assim, a distinção, proposta por Price, entre texto e livro, para pensar o problema do sentido, descartando sua localização no texto, para situá-lo no jogo entre livro, texto e alguns outros elementos que serão trabalhados adiante.

\section{Os Evangelhos: Kells}


Figura 1: Folios 34R (Chi Rho) e 285R (Una autem sabbati valde) do Livro de Kells.

Assim como a origem geográfica, a datação é problemática, mas sua produção se situa entre os séculos VI e IX da era cristã, mais provavelmente em

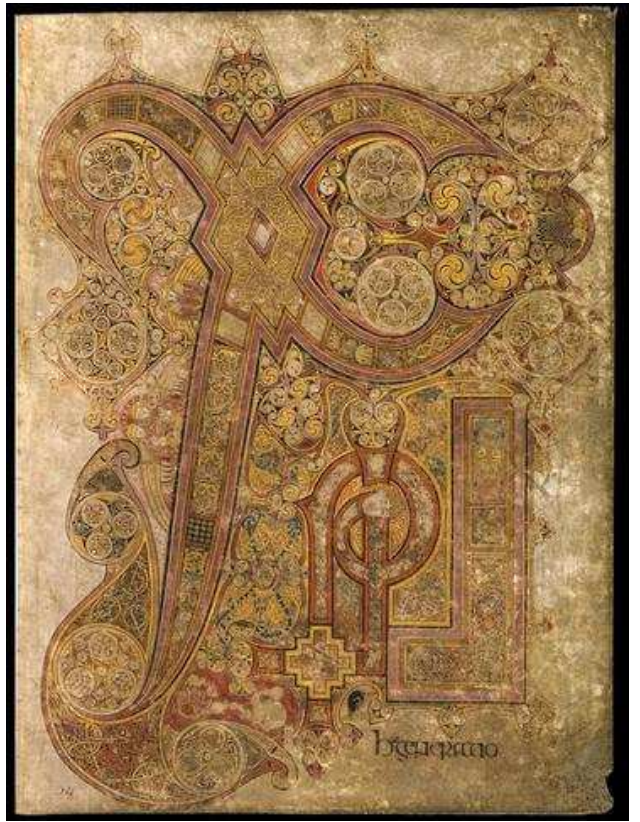

Fonte:

http://digitalcollections.tcd.ie/home/index.php?DRIS_ID= MS58_003v Acesso em 04 jul. 2016

Os quatro Evangelhos, núcleo central do Novo Testamento, são um texto tanto antigo quanto comumente editado. As edições são várias e o material foi amplamente publicado, lido, circulado, comprado, emprestado, roubado, comentado e pirateado. Não se trata de um texto cujo estabelecimento seja totalmente consensual, as variantes abundam.

A primeira apresentação dos Evangelhos a ser aqui trabalhada se faz em um livro bastante famoso, o livro de Kells, códice medieval irlandês. Uma versão digital fica acessível nas coleções digitais do Trinity College(http://digitalcollections.tcd.ie/home/index.php ?DRIS_ID=MS58_003v).

A origem do livro de Kells é incerta e grosso modo quatro possibilidades podem ser consideradas: o livro teria sido escrito em lona, o livro teria sido escrito em Kells, o livro teria sido iniciado em lona e continuado em Kells, o livro teria sido produzido na Nortúmbria. De todo modo, é certo que no ano 1007 estava em Kells e que foi posteriormente para Dublin, onde está até hoje. torno da passagem do VII para o VIII.

Possivelmente três copistas e três ilustradores diferentes trabalharam na elaboração do manuscrito.

Materialmente, o livro é composto por 340 fólios de velino de diversas qualidades, medindo atualmente $33 \times 25$ centímetros. As páginas foram aparadas no século XVIII para padronização de seu tamanho e deviam ter priginalmente $37 X 26$ centímetros. muitos buracos e irregularidades em diversos fólios, muitas costuras e remendos.

Globalmente, para a maior parte do texto, é utilizada uma escrita em maiúsculas insulares, mas outras são encontradas ocasionalmente. Há muitas ligaturas e abreviações.

O Livro de Kells é ricamente ilustrado: há páginas inteiras de ilustração, grandes iniciais ornadas, muito uso de ilustrações durante o texto. Pigmentos de diversos tipos, alguns produzidos longe das ilhas britânicas, foram utilizados. Não há uso de ouro no exemplar, apenas ouro pigmento (orpiment). O texto vem em coluna única e as divisões entre trechos não são padronizadas, sendo feitas com ilustrações, letras ornadas etc. Atualmente, as margens, muito variáveis, estão em torno de 8 centímetros.

Aparentemente, o plano original era fazer preceder cada Evangelho de uma página com 92 Jlos ligados ao evangelista autor, uma com um ıerraı e uma página decorada com as palavras ou letras iniciais do texto. Tal plano não foi totalmente levado a cabo.

O conteúdo é composto essencialmente pelos quatro Evangelhos, listas de nomes hebreus dos Evangelhos (Folios 1R e 26) divididas por Evangelhos 
sendo duas totalmente ausentes e duas incompletas, Tábuas canônicas incompletas, um texto comumente chamado de Breves Causae (espécie de resumo de traduções antigas dos Evangelhos) e um texto nomeado Argumenta (lendas sobre os evangelistas). Note-se que o Evangelho de João está incompleto pois toda a parte final foi perdida. O texto é o da Vulgata mas com variações, algo relativamente comum nos manuscritos insulares.

Há muitos erros de cópia e o texto está inacabado. As tábuas de concordância, por exemplo, não podem ser utilizadas pois a numeração que permitiria a referenciação está ausente.

Além dos textos originais, vários elementos foram acrescentados posteriormente na história de vida do livro, tais como cartas de posse do mosteiro de Kells copiadas em trechos vazios, assinaturas, numeração de fólios etc.

O livro de Kells possuía uma capa ricamente decorada, o que teria feito com que fosse furtado no ano de 1007. Os Anais de Ulster assim registram os fatos:

O Grande Evangelho de Columba foi pecaminosamente roubado à noite da sacristia oeste da grande igreja de pedra de Kells. Era o objeto mais precioso do mundo ocidental em termos de ornamentação humana. Esse Evangelho foi recuperado depois de dois meses e vinte noites, enterrado na grama, tendo seu ouro [capa] sido retirado (Annals of Ulster, acesso em 04 jul. 2016. Na tradução, modernizamos os nomes e o texto).

Como o manuscrito foi recuperado posteriormente sem a capa (seu ouro) e como não há descrições desta, só se pode, hoje, imaginar o valor, certamente elevado, e a beleza do objeto. Se a capa era tão mais magnífica do que o livro, é mesmo difícil conceber sua riqueza.

Textos contendo Evangelhos, Breves Causae, Argumenta entre outros poderiam se destinar a diferentes usos no contexto medieval: leitura e meditação individual; leitura oralizada pública entre monges e entre monges e leigos; uso no ensino; uso na conversão de pagãos; uso litúrgico e assim sucessivamente.

Considerando o livro de Kells, podemos excluir algumas utilizações.
A leitura e a meditação individuais eram pouco prováveis em razão do número excessivo de erros, do caráter incompleto do texto, da não finalização das tábuas de concordância etc. Dificilmente o livro se prestaria a tais usos. Ou seja, o livro não seria adequado para trabalho intelectual e espiritual.

Pelos mesmos motivos exclui-se o uso no ensino.

O uso na conversão de pagãos pode ser excluído dado o caráter rico e valioso do livro: seria perigoso viajar para pregação e conversão com uma tal preciosidade.

Seu uso era muito provavelmente litúrgico. Servia para leitura ou, sobretudo, como aide mémoire durante a missa. Além disso, era prova da força espiritual e material de seu mosteiro: um tal objeto não se produzia sem recursos tanto físicos quanto devocionais.

Sustentamos aqui que seu sentido estava articulado a esse uso litúrgico, que sua apreensão social e individual se ligava mais propriamente a essa dimensão cristã espetacular de fé do que ao ato cognitivo de ler.

Perguntar pelo sentido do livro de Kells envolve portanto considerar não propriamente o texto e sua leitura, mas o modo como o texto e o livro, este em sua radical singularidade, existiam no contexto medieval, representando o que representavam, apontando, mesmo para quem não sabia ler, para onde apontavam.

\section{A edição contemporânea impressa da Bíblia}

Figura 2: Exemplar impresso. 


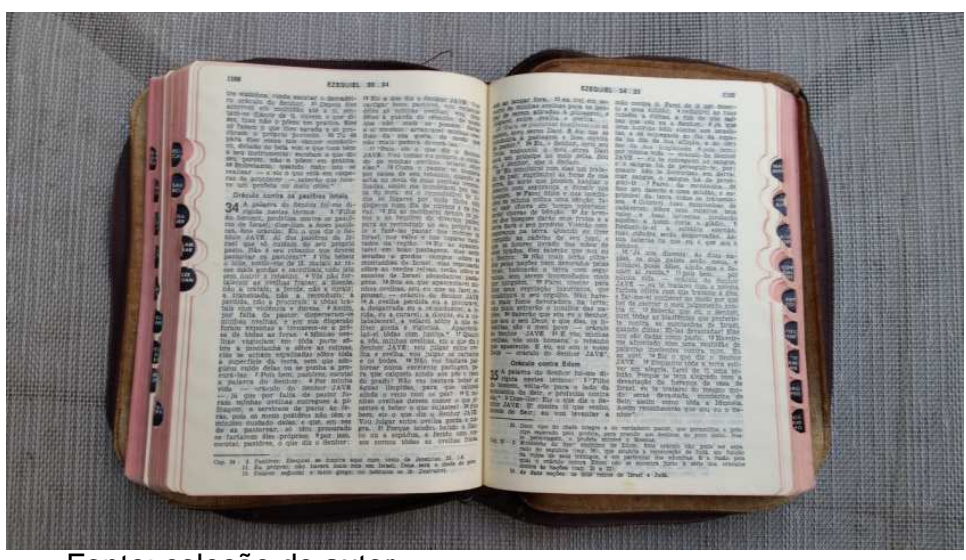

Fonte: coleção do autor

O segundo objeto contendo os Evangelhos a ser aqui considerado é uma Bíblia Sagrada, editada pela Editora Ave Maria Ltda, na cidade de São Paulo, no ano de 1988.

Trata-se de uma edição impressa do texto bíblico acompanhado de extenso material de apoio: "Ordem alfabética dos 73 livros da Bíblia", "Constituição dogmática Dei Verbum sobre a Revelação Divina", página de título detalhada no verso da qual temos Nihil Obstat, Imprimi Potest e Imprimatur, "Prólogo à Tradução", “Índice”, "As Grandes Datas da Bíblia", "Como ler a sagrada Bíblia", "Como ler as citações", "Introdução Geral: História dos Hebreus, A Bíblia em Geral", "Introdução Particular aos Livros do Antigo Testamento", "Introdução Particular aos Livros do Novo Testamento". O texto do Antigo Testamento propriamente dito começa na página 49. Seguem-se ao texto do Novo Testamento: "Índice Doutrinal", "Calendário Hebraico", "Medidas e Moedas", "Genealogia Bíblica", "Tabela das Leituras Bíblicas Litúrgicas até o ano 2000", "Acompanhando a Vida Espiritual da Igreja com a Bíblia na Mão: Leituras Litúrgicas", "Mapas e cartas da antiguidade".

O papel mede $18 \times 13,2$ centímetros e a capa tem cerca de meio centímetro de cada lado a mais em relação ao papel. As margens são variáveis, em torno de uma medida média de: centro 0,5; altc 93 exterior 1,5; e baixo 0,7 centímetros.

O texto tem, em geral, duas colunas, excepcionalmente uma em certos trechos (partes pré e pós textual e alguns trechos da Bíblia propriamente dita). Obviamente, sendo uma edição contemporânea, apresenta separação de palavras, pontuação e paginação, indicação de capítulos, subcapítulos etc. Não há ilustrações. Destaque-se um mecanismo de localização no texto composto por orifícios semicirculares cortados nas páginas como indicação de onde começam certos trechos.

Quanto à utilização do texto, exceto pelo o fato de que a capa incomoda um pouco e de que os orifícios de navegação ajudam, é como o de qualquer códice impresso contemporâneo. As marcas de posse e utilização são poucas: nome da proprietária escrito a lápis na primeira página, pontos discretos sobre certos trechos do texto. O livro não carrega muitos testemunhos de sua vida pregressa.

O contexto de aquisição e leitura desse exemplar é o da última década do século passado e dos primeiros anos do século XXI. Trata-se, segundo foi por nós levantado, de um livro de uso religioso pessoal, para leitura individual e também coletiva (novenas etc). Diferentemente do livro de Kells, a dimensão de livro-espetáculo não se faz presente (a capa não chega a fazer dessa edição uma edição espetacular).

Seu uso individual, de leitura solitária, envolvia certamente uma dimensão de crença e fé, possivelmente de oração, dado que esse livro convivia, diariamente, com uma série de outros símbolos religiosos (terços, imagens, panfletos etc), como tivemos a ocasião de constatar em uma situação de observação. Mas ao mesmo tempo, o livro era utilizado em vários eventos que, além de religiosos, tinham um caráter forte de espaços de sociabilidade.

Quando se pensa sobre seu sentido, desse modo, devem ser levados em conta esses dois traços: diferentemente do Livro de Kells, não se trata de um livro para uso litúrgico e que presentificaria a força tanto da Igreja quanto do Deus cristão; trata-se, 94 i, de um livro para uso privado de devoção ou a em círculos restritos de sociabilidade religiosa. Se o sentido é, como aqui se sustenta, indissociável dos usos, Kells e nosso exemplar impresso tem sentidos diferentes. 


\section{Evangelhos digitais}

Figura 3: Exemplar digital.

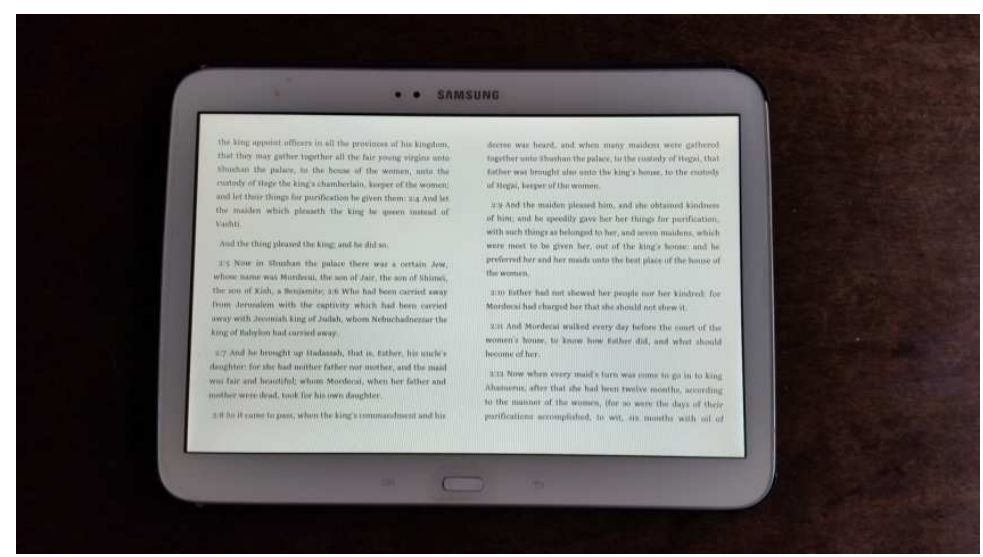

Fonte: coleção do autor

A terceira apresentação dos Evangelhos aqui em discussão difere ligeiramente das duas anteriores. Não temos aqui um livro indissociavelmente ligado a um texto, como no caso do manuscrito ou do impresso, mas um aparelho que permite a leitura de textos codificados digitalmente.

Os Evangelhos virtuais selecionados estão contidos na Bíblia do Rei Jaime disponibilizada pelo Projeto Gutenberg (PROJECT GUTENBERG, 2011), sendo esta Bíblia o segundo resultado de uma pesquisa feita no Google com os termos "bible" e "epub" (o primeiro era uma enorme lista de Bíblias digitais em quase 700 línguas diferentes). Havia, quando da coleta do arquivo, vários formatos possíveis: Html, Epub (com imagens), Epub (sem imagens), Kindle (com imagens), Kindle (sem imagens), Plain Text etc e foi baixado o formato Epub3, sem imagens. Sendo uma Bíblia completa, os Evangelhos estão precedidos pelo Antigo Testamento e são sucedidos pelo resto do Novo. Como ferramenta de apresentação, como livro, foi utilizado um Tablet Samsung Galaxy Tab 3, modelo GTP5210, versão do Android 4.4.2, com aplicativo Play Livros.

Como recursos digitais são oferecidos: marcação de página, leitura em voz alta do texto pelo aplicativo (não muito agradável), alteração da luminosidade da tela, da cor do fundo, iluminação noturna (que adapta a cor da tela à luminosidade ambiente em função do ciclo dia/noite), alteração do tipo e tamanho de caractere, espaço entre linhas e justificação, dicionário ativado quando se marca uma palavra no texto (online e offline), marcação de trechos do texto com diferentes cores, busca, tradução automática de palavras ou trechos, cópia de palavras ou trechos, anotações, sincronização do arquivo que se lê com o mesmo arquivo em outros dispositivos (celular, por exemplo) e navegação dentro do texto através de um botão em uma barra.

O texto da Bíblia propriamente dito é precedido de uma nota explicativa do Gutenberg Project e de um sumário. Ao se tocar em um título do sumário, automaticamente 0 aparelho abre a página correspondente. $\mathrm{O}$ material é organizado com títulos e subtítulos claramente distintos e traz a numeração de capítulos e versículos. Findo o último livro bíblico, encontra-se uma longa nota de explicação das edições digitais do Projeto e das licenças de utilização etc. No topo da última página o aplicativo pergunta "Pronto para começar seu próximo livro?".

Trata-se de uma apresentação dos Evangelhos que pode se prestar aos mais variados usos. Sem a pretensão de exaustividade, é possível uma leitura através da função de leitura em voz alta pelo aplicativo (como dito acima, não muito agradável, mas mesmo assim realizável); é possível uma leitura individual que se poderia caracterizar por intensiva por parte de um religioso; é possível um uso extensivo, em que o leitor flana pelo texto usando os recursos de navegação, sumário, procura etc; é igualmente possível uma leitura coletiva em que pode ser discutida, com a ajuda de dicionários, a significação de trechos específicos; é possível uma leitura estudiosa erudita em que são verificadas, com a função de busca, por exemplo, todas as ocorrências de um determinado termo, com vistas a se estabelecer possíveis flutuações semânticas etc. Todos esses usos podem envolver a tomada de notas e a marcação de trechos ou páginas, com eventual uso de cores para diferentes tipos de marcação (possíveis citações em uma cor, trechos morais em outra e assim por diante). 
O contexto específico de uso desse livro é o de pesquisa, não sendo portanto um exemplar destinado a uma leitura espiritual ou mística, nem previsto para uso em eventos sociais de caráter devocional, como o exemplar impresso acima. Colaboram para esse uso de pesquisa todos os recursos disponibilizados, além da portabilidade, recursos que, é preciso que se diga, são comuns à maioria dos tablets e aparelhos de leitura disponíveis no mercado.

Seu sentido, ou seus sentidos, desse modo, necessariamente se situa em uma dimensão diferente dos dois primeiros casos, já que o aspecto religioso propriamente dito se encontra ausente. Note-se que quando aqui falamos do sentido deste livro levamos em conta seu contexto de uso e de leitura.

\section{Três livros diferentes: a materialidade e o sentido}

O texto dos Evangelhos não é exatamente o mesmo nos três objetos de apresentação textual de que nos ocupamos acima. Em primeiro lugar, há a diferença de língua: latim, para o primeiro, português, para o segundo, inglês, para o terceiro. Mas se descartamos essa diferença de língua como menos interessante, outras diferenças entre esses textos podem ser indicadas, na medida em que estamos diante de três versões diferentes do texto bíblico: em Kells, a vulgata misturada a edições latinas anteriores; no impresso, a versão dos monges Maredsous (Bélgica); no digital, a versão anglicana comandada por pelo rei Jaime. Três variações sobre o mesmo tema, portanto, para utilizar uma expressão musical.

Essas diferenças não são surpreendentes se se considera a distância que separa essas versões do texto: uma medieval, uma do século XVII e outra do $\mathrm{XX}$.

Vamos aqui, porém, deixar de lado essas diferenças textuais, tratando os três livros como variações sobre o mesmo tema, como dito acima, considerando que, grosso modo, para o que neste artigo se discute, são os Evangelhos apresentados em diferentes livros e acompanhados de diferentes complementos (Argumentos, Antigo Testamento etc).

Assim, voltamos nosso olhar para os objetos, deixando de lado os textos que contém. Os livros que apresentam esses textos foram estrategicamente escolhidos para que se pudesse realizar a comparação de objetos vindos de contextos diferentes e materialmente bastante diversos.

Ora, parece relativamente evidente que os Evangelhos podem ter sentidos diferentes em lugares diferentes, épocas diferentes e lidos por leitores diferentes. Dispensamo-nos de discutir esse ponto tomando-o como um pressuposto: um texto pode, assim, tomar diferentes sentidos. Assim, essas três apresentações dos Evangelhos, materialmente diferentes, existindo em situações diversas, certamente deram ensejo a práticas de sentido diferentes, ou seja, foram lidas ou interpretadas ou vividas de modos heterogêneos.

A pergunta que se coloca, dado isso, é: que elementos participam desse processo diferencial de geração de sentido? Como fazer um mapeamento desses elementos?

Vamos organizar a discussão em torno de quatro eixos básicos que permitem, cada um em sua relativa generalidade, um encaminhamento de resposta.

O elemento texto, obviamente, é essencial na produção de sentido, não poderia deixar de sê-lo, mas uma vez que tradicionalmente já é aceito como tal, não o discutiremos aqui.

O segundo elemento é o livro em que o texto aparece.

O livro de Kells é paradigmático para essa questão, pois não era um livro destinado primordialmente à leitura. Como vimos acima, o excesso de erros no texto, as ilustrações e a diagramação, a incompletude das tábuas de concordância, complicavam o ato de ler: "inumeráveis erros, ilustrações prejudicando a legibilidade, formato excessivamente grande, o Livro de Kells não parece destinado à leitura" (MICHEL, acesso em 06 jul. 2016, p. 102). 
Essa não destinação à leitura não implica em que um livro não participe de práticas de produção de sentido. No caso do Livro de Kells, uma primeira dessas práticas envolveria seu uso durante a missa ou em outros rituais cristãos. Assim, o livro poderia funcionar como suporte de memória, como vimos, para a recitação durante a missa de trechos que o oficiante conhecia de cor. Tenha-se em mente, quanto a isso, que o livro foi roubado, em 1007, da sacristia, local onde são normalmente armazenados os objetos utilizados durante o culto. Além de suporte de memória, o livro, como indicado acima, por seu próprio caráter espetacular, ricamente ilustrado etc, seria ao mesmo tempo homenagem à gloria de Deus por parte dos que o criaram e símbolo da força desse mesmo Deus. E, claro, da igreja de Kells. Esse caráter simbólico e ostentatório do objeto certamente agiu durante o culto mas também em situações mais prosaicas (atraindo potenciais vocações religiosas ou pessoas para seguirem algum tipo de educação no mosteiro, por exemplo).

O livro de Kells mostra bem como o caráter material do livro produz sentido, faz sentido, mesmo para os que não o leem diretamente. Claro é, pela natureza tanto do texto quando do livro, que esse sentido remetia para o campo religioso.

Além disso, podemos afirmar que virtualmente tudo da materialidade pode ser relevante. Assim, por exemplo, o tipo de recurso disponibilizado: as tábuas de concordância incompletas do livro de Kells impedem um uso deste livro para estudo e comparação dos Evangelhos, o que a edição digital facilita imensamente, tornando o trabalho intelectual com o texto mais eficaz. Um certo tipo de navegação à procura de termos é muito mais prático dentro da edição do rei Jaime aqui analisada, o diagrama de produção de sentido, assim, é outro em relação ao livro de Kells.

Por outro lado, e mais uma vez saímos do espaço da leitura propriamente dita, a edição impressa, com sua capa de couro e seu caráter austero e discreto e, ao mesmo tempo, bastante portável, se adéqua bem a uma produção de sentido muito mais religiosa e coletiva em uma leitura ou recitação conjunta, eventualmente murmurada, em uma novena. Aqui mais uma vez, o objeto impresso pode funcionar como auxílio mnemônico e apoio mais do que como condição sine qua non, dado que as palavras envolvidas certamente eram conhecidas do usuário.

Assim, em suma, a materialidade do objeto pode e deve ser levada em conta para a compreensão dos processos de produção de sentido. Mas se a materialidade certamente é um elemento a ser considerado, se o sentido envolve também o livro além do texto, é preciso avançar na discussão pois não se pode hipervalorizar a conformação material, em uma hipertrofia dos meios, em detrimento tanto dos conteúdos quando dos agentes humanos.

\section{Agentes humanos e sentido}

Todo um universo de aspectos humanos deve entrar na equação que tenta dar conta da criação de sentidos. Essa dimensão humana pode, esquematicamente, ser pensada em dois níveis.

Há, em primeiro lugar, um nível idiossincrático, que remete para a individualidade específica de cada sujeito que, em uma dada situação, se relaciona com um livro. Esses traços idiossincráticos englobam fatores de psicologia individual, motivação para a leitura, história de leituras passadas, interesse pelo texto, preferências em relação ao livro (gostar ou não de digital e tudo que envolve a materialidade) entre outras coisas. Assim, primeiro campo relevante no que concerne a ação humana, 0 individual $e$ idiossincrático.

Além disso, todo o campo do social, ou do coletivo, se se quiser, importa de diferentes modos. Note-se, evidentemente, que esse coletivo afeta 0 individual. Há claramente um coletivo mais imediato, que envolve os subgrupos socio-profissionais a que um leitor pertence (professores universitários por exemplo), família, relações de amizade etc. Esse grupo mais imediato se relaciona com grupos mais amplos, ser habitante do Rio de Janeiro, ser brasileiro, e esses grupos mais amplos, do mesmo modo, devem ser considerados. 
É preciso ter em mente que o grupo social ou coletivo, seja amplo, seja restrito, é atravessado por questões individuais, e vice-versa, de modo que os resultados de produção de sentido para um mesmo livro podem ser muito diferentes ou mesmo paradoxais: dois colegas de trabalho, de mesmo nível social, econômico e educacional, podem interpretar a mesma obra de um determinado autor de maneiras totalmente opostas (o que alias é a riqueza do campo intelectual, que por isso mesmo não se fecha em dogmatismos).

\section{Conclusão}

Partimos da distinção entre livro e texto para tomar como casos de análise três apresentações diferentes dos Evangelhos. Essas análises dos casos tinham como horizonte de discussão a produção do sentido, tendo como pressuposto o fato de que o texto, por si só e abstratamente, não era o detentor do sentido a ser agenciado nos atos de leitura.

Vimos como três campos fundamentais, além do texto, devem ser tomados em conta: o campo do livro, entendido como objeto material que apresenta uma obra qualquer; o campo das características da pessoa que opera sobre o livro, incluindo-se aí as condições individuais em que a leitura se dá; e, finalmente, o campo social, que engloba desde os micro-grupos familiares ou de amizade até aspectos macro de pertencimento a grandes coletivos sociais.

Algumas questões interessantes, isso posto, se abrem para a pesquisa. Indicamos aqui apenas uma, conceitual, que envolve o estabelecimento de uma definição apropriada do que se pode entender por sentido. Essa discussão semântica e de conceito pode estar na base de uma série de confusões teóricas mais ou menos relevantes. Assim, para citar um exemplo, toda a condenação do pensamento ocidental em Gumbrecht (2004) repousa sobre uma visão de sentido muito restrita, algo como encadeamento lógico proposicional, que certamente não dá conta de uma série de práticas literárias e de relacionamento com livros que fazem parte de nossa história. O sentido deve ser pensado como mais do que isso, como desenhamos brevemente na discussão dos três casos acima, mas aqui não dispomos de tempo ou espaço para adentrar profundamente essa discussão. Tal definição de um conceito claro de sentido deve, naturalmente, dialogar com uma série de campos e não pode ser empreendida no espaço restrito de um campo teórico isolado, donde a necessidade de uma troca profunda entre variadas especialidades.

Encerramos aqui menos com a impressão de ter concluído algo e mais com a certeza de termos apenas esboçado um problema e uma proposta de esquematização de resposta, restando ainda muito trabalho por se fazer.

\section{Referências}

Annals of Ulster. [s.I.]: [s.d.] Disponível em http://www.ucc.ie/celt/online/T100001A/ . Acesso em: 04 jul. 2016.

GONÇALVES, Márcio Souza; TIMPONI, Raquel. Suportes textuais de comunicação e processos cognitivos. In: REGIS, Fátima; ORTIZ, Anderson; AFFONSO, Luiz Carlos; TIMPONI, Raquel. (Orgs.). Tecnologias de Comunicação e Cognição. 1. ed. Porto Alegre: Sulina, 2012. 381 p. p. 52-78.

GUMBRECHT, Hans Ulrich. Production of Presence What Meaning Cannot Convey. 1. ed. Stanford: Stanford University Press, 2004. 180 p.

MICHEL, Marie. La place du livre dans la société médiévale: le livre trésor - Étude à travers l'exemple du Livre de Kells. 1. ed. Grenoble: Université Grenoble Alpes - UFR Sciences Humaines, [s.d]. Disponível em http://dumas.ccsd.cnrs.fr/dumas-00406915/en/ . Acesso em: 06 jul. 2016.

PRICE, Leah. How to do things with books in Victorian Britain. 1. ed. Princeton e Oxford: Princeton University Press, 2013. 350 p.

The King James Version of the Bible. Salt Lake City: Gutenberg Project, 2011. Disponível em http://www.gutenberg.org/ebooks/10 . Acesso em: 30 jun. 2016. 


\section{COMO CITAR ESSE ARTIGO}

GONÇALVES, Márcio Souza. O texto, o livro, o sentido e o leitor. Signo, Santa Cruz do Sul, v. 43, n. 76, mar. 2018. ISSN 1982-2014. Disponível em: <https://online.unisc.br/seer/index.php/signo/article/view/11156>. Acesso em: . doi: http://dx.doi.org/10.17058/signo.v43i76.11156. 